\title{
Boxing Injuries in the Army
}

\author{
Mr B J Oelman \\ MSc \\ Miss C M E Rose \\ Miss $\mathrm{K} \mathrm{J}$ Arlow \\ Ministry of Defence, (Stats $(G) 4)$, Stanmore
}

SUMMARY: Boxing injuries in the Army were studied over the period 1969-1980. On average there were 35 cases a year each spending an average of 10.4 days in hospital. There were no deaths but there were 10 medical discharges due to injuries sustained from boxing during the period. Head injuries predominated and occurred relatively more frequently in the young and inexperienced boxers.

\section{Introduction}

The recent death of a junior soldier following a civilian boxing match raises the question of the safety of boxing as a sport. Rosenbaum ${ }^{1}$ found that in 1962, in terms of injuries received per period played, boxing was less dangerous than skiing, rugby football and association football. We decided to look at the different types of injury received, the length of stay in medical units and the final disposal of the patients.

\section{Methods}

In Stats (G) 4 we hold records (F Meds 14) of all admissions to Hospitals and Medical Reception Stations of Service Personnel for two days or more. Information on types of disease/injury (using $\mathrm{ICD}^{2}$ codes), causes of injury and various items of personal information (name, number, age etc) are extracted from the records and held on a computer.
For this study we retrieved details of all Army personnel admitted because of boxing injuries during the years $1969-1980$ or who died or were medically discharged between 1952 and 1980 .

In most instances we have restricted ourselves to the computer held data for those patients who were admitted but for unusual cases and the medical discharges after 1967 we have examined the F Med $14 \mathrm{~s}, \mathrm{~F}$ Med 23s (records of medical board proceedings) and any other relevant records held in the branch.

Durations of stay include both the day of admission to a medical unit and the day on which the patient was discharged.

\section{Admissions}

During the 12 year period under consideration (1969-1980) there were 437 admissions. Table 1 shows the distribution of the injuries by year and

Table 1

Admissions to Medical Unit from Boxing Injuries Army Personnel 1969-1980

\begin{tabular}{lccccccc}
\hline Year & $\begin{array}{c}\text { Site } \\
\text { Total }\end{array}$ & Head & $\begin{array}{c}\text { Upper } \\
\text { Limb }\end{array}$ & $\begin{array}{c}\text { Lower } \\
\text { Limb }\end{array}$ & Trunk & Internal & Other \\
\hline 1969 & 53 & 35 & 9 & 2 & 2 & 1 & 4 \\
1970 & 34 & 20 & 6 & 1 & 3 & 1 & 3 \\
1971 & 18 & 11 & 4 & 0 & 0 & 0 & 3 \\
1972 & 40 & 28 & 5 & 1 & 1 & 1 & 4 \\
1973 & 27 & 18 & 4 & 2 & 0 & 1 & 2 \\
1974 & 24 & 11 & 3 & 3 & 6 & 0 & 1 \\
1975 & 34 & 26 & 4 & 1 & 1 & 2 & 0 \\
1976 & 26 & 18 & 4 & 0 & 2 & 2 & 3 \\
1977 & 43 & 32 & 2 & 5 & 0 & 2 & 2 \\
1978 & 47 & 30 & 7 & 2 & 2 & 2 & 2 \\
1979 & 36 & 29 & 2 & 2 & 1 & 0 & 2 \\
1980 & 54 & 38 & 9 & 2 & 2 & 20 & 1 \\
\hline Totals & 437 & 296 & 59 & 21 & 20 & 13 & $(6.4)$ \\
(\%) & & $(67.7)$ & $(13.5)$ & $(4.8)$ & $(4.6)$ & $(3.0)$ & $(6.4)$ \\
\hline
\end{tabular}


site. There is no obvious trend over time for the number of injuries or between types of injury but, as might be expected, head injuries predominated and accounted for some $67.7 \%$ of all admissions. Table II gives the total cases and inpatient days for selected diagnoses. (code 921$), 2$ cases $(0.68 \%)$ of cerebral laceration and contusion (code 851 ) of which one resulted in a medical discharge, and $3(1 \%)$ cases of subdural haemorrhage (code 852) all of which resulted in medical discharges. The others were made up of a miscellaneous collection ranging from 2 cases of

Table II

Number of Admissions and Inpatient Days for Selected Diagnosis for Boxing Injuries, Army Personnel 1969-1980

\begin{tabular}{|c|c|c|c|c|}
\hline Diagnosis & $\begin{array}{l}\text { ICD Code } \\
\text { Ninth Edition }\end{array}$ & $\begin{array}{l}\text { Number of } \\
\text { Admissions }\end{array}$ & $\begin{array}{c}\text { Total } \\
\text { Inpatient } \\
\text { Days }\end{array}$ & $\begin{array}{c}\text { Average } \\
\text { Inpatient } \\
\text { Days }\end{array}$ \\
\hline Total & 一 & 437 & 4540 & 10.4 \\
\hline Head Injuries & - & 296 & 2595 & 8.8 \\
\hline Fracture of Face Bones & 802 & 83 & 737 & 8.9 \\
\hline Concussion & 850 & 115 & 4.50 & 3.9 \\
\hline Cerebral laceration and contusion & 851 & 2 & 484 & 242.0 \\
\hline Subdural haemorrhage & 852 & 3 & 178 & 59.3 \\
\hline Other Intracranial Injury & 854 & 69 & 592 & 8.6 \\
\hline Contusion of Face Scalp and Neck & 920 & 13 & 104 & 8.0 \\
\hline Other & - & 11 & 50 & 4.5 \\
\hline Upper Limb Injuries & - & 59 & 740 & 12.5 \\
\hline Fracture of humerus & 812 & 1 & 21 & 21.0 \\
\hline Fracture of radius and ulna & 813 & 3 & 48 & 16.0 \\
\hline Fracture of metacarpal bones & 815 & 28 & 342 & 12.2 \\
\hline Open wound of elbow forearm and wrist & 881 & 2 & 177 & 88.5 \\
\hline Other & - & 25 & 152 & 6.1 \\
\hline Lower Limb Injuries & - & 21 & 580 & 27.6 \\
\hline Fracture and tibia and fibula & 823 & 3 & 136 & 45.3 \\
\hline Dislocation of knee & 836 & 7 & 248 & 35.4 \\
\hline Sprains and strains of knee and leg & 844 & 3 & 152 & 50.7 \\
\hline Other & - & 8 & 44 & 5.5 \\
\hline Trunk Injuries & & 20 & 365 & 18.3 \\
\hline Spondylosis & 713 & 1 & 153 & 153.0 \\
\hline $\begin{array}{l}\text { Fracture or fracture disclocation of the vertebral } \\
\text { column without spinal lesion. }\end{array}$ & 805 & 2 & 45 & 22.5 \\
\hline Fracture of the ribs or larynx & 807 & 3 & 40 & 13.3 \\
\hline Spinal cord lesion & 958 & 1 & 33 & 33.0 \\
\hline Other & - & 13 & 94 & 7.2 \\
\hline [nternal Injuries & - & 13 & 81 & 6.2 \\
\hline 'Other” Injuries & - & 28 & 179 & 6.4 \\
\hline Injuries other and unspecified & 959 & 21 & 125 & 6.0 \\
\hline
\end{tabular}

Note: Conditions for inclusion of specific diagnosis - twelve or more cases during the period or an average of ten or more a day in hospital.

There were 296 head injuries made up of 83 (28\%) fractures of the face bones (ICD code 802 ), $115(39 \%)$ cases of concussion (code 850$), 69(23 \%)$ cases of "intracranial injury of other and unspecified nature" (code 854$), 13(14.4 \%$ ) cases of contusion of face, scalp and neck (code 920), 5 $(1.7 \%)$ cases of contusion of the eye and orbit open wound of ear (code 872) to one crushing injury of face, scalp and neck (code 925).

The average length of stay for head injuries was 8.77 days. The highest average length of stay was 242 days for cerebral laceration and contusion but one of the cases was in hospital for 471 days before being medically discharged from the Army. 
The fractured face bones cases stayed for 8.88 days and the concussion patients for 3.91 days on average. The other intracranial injuries averaged 8.58 days with a maximum of 21 days. The other high average of this group was 59.3 days for three cases of subdural haemorrhage, all resulting in medical discharge.

Of the 59 upper limb injury admissions 28 $(47.5 \%)$ were for fractured metacarpal bones (code 815) and these cases averaged 12.2 days in hospital. The other cases were for various minor fractures, dislocations, sprains, strains and contusions and the only groups of any note were $8(13.6 \%)$ cases of fractured fingers or thumbs (code 816) and $9(15.3 \%)$ cases of dislocated shoulders (code 831 ). Of the two cases of open wounds of the upper limb (code 881) one case of laceration of the right wrist was in hospital for 174 days before being medically discharged. This accounts for the high average stay (12.5 days) for arm injuries.

There were only 21 injuries to the lower limbs and no large group, however, 3 cases of fractured tibia and fibula (code 823) involved a total of 136

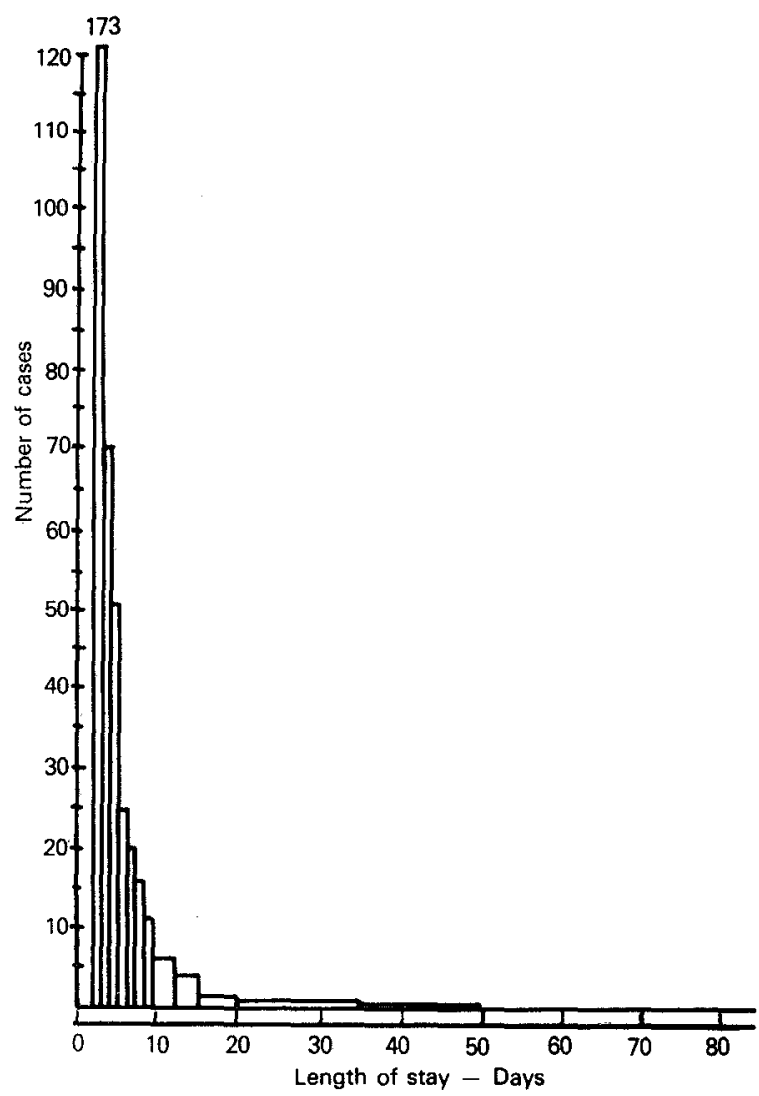

Fig. 1 Number of cases by length of stay days in hospital and 7 cases of dislocated knee (code 836) totalled 248 days. One of these cases was medically discharged after 82 days in hospital and another required extensive rehabilitation with a total stay of 84 days. There were 3 cases of sprains and strains to the knee and leg (code 844) involving 152 days in hospital but this was inflated by one of the cases which required an operation on the patella ligament and joint capsule followed by physiotherapy, the total stay being 143 days.

There were 20 admissions for injuries to the trunk with contusions (code 922) accounting for 7 of them. Of the remainder 2 fractures of the vertebral column (code 805), one case of spondylosis (code 713), and one case of spinal cord lesion (code 952) were the more serious cases. The latter two cases resulted in medical discharges.

Internal injuries accounted for only 13 of the cases and there were no outstanding types either for number or length of stay. The injuries varied between injuries to kidneys (4) to those of the pelvic organs (3). Average length of stay was 6.23 days.

The "Other" injuries group consists mainly of those injuries where sufficient information was not given on the records received for us to determine

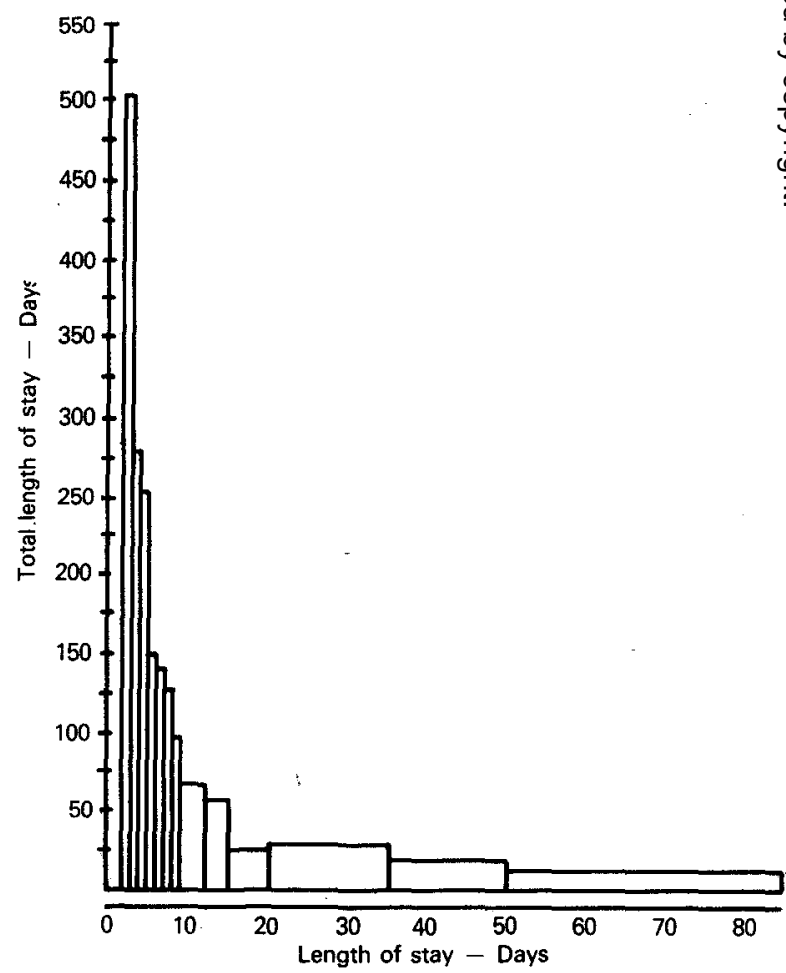

Fig. 2 Total stay by length of stay 
the location and nature of the injury. All the cases were of short duration.

Fig. 1 shows number of cases with each length of stay. It can be seen that 173 out of the 437 cases $(40 \%)$ only stayed in hospital for three days (note that (1) both the day of discharge and the day of admission are counted and thus three days stay represents only two nights in hospital and (2) no cases of two days or less are included in the study). A further $16 \%$ of cases were in for only four days and $90 \%$ of cases were discharged within two weeks of admission.

Fig. 2 shows the same data but highlighting the total length of stay in each group. Thus although only $10(2 \%)$ cases had lengths of stay of more than 50 days they accounted for $39 \%$ of the total days in hospital.

\section{Medical Discharges and Deaths}

During the 29 year period from 1952 to 1980 no deaths occurred in the Army as a result of injuries received while boxing. There were, however, 29 injuries serious enough to result in the patient being medically discharged from the Service. Details of these cases are given in table 3 . The cases were evenly spread over the period and there is no evidence to suggest either a rising or falling trend. There also seems to be no trend in the type of injury for which people are being discharged.

The majority of discharges (16 out of $29,55 \%$ ) were to patients suffering from injuries to the head and 7 of these were for intracranial haemorrhage. The remaining cases were mainly for fractures, dislocations and sprains. Most of the discharges occurred after long hospital stays. Conversely many

Table III

Medical Discharges 1952-1980

\begin{tabular}{|c|c|c|c|c|c|c|}
\hline $\begin{array}{l}\text { Year of } \\
\text { Discharge }\end{array}$ & $\begin{array}{c}\text { Year of } \\
\text { Injury } \\
\left(1^{*}\right)\end{array}$ & $\begin{array}{c}\text { Age at } \\
\text { time of } \\
\text { Discharge }\end{array}$ & $\begin{array}{c}\text { Princ Dis } \\
\text { at } \\
\text { Discharge } \\
\text { ICD Code } \\
\left(2^{*}\right) \\
\end{array}$ & $\begin{array}{c}\text { Sec Dis } \\
\text { at } \\
\text { Discharge } \\
\text { ICD Code } \\
\left(2^{*}\right) \\
\end{array}$ & $\begin{array}{l}\text { Princ Dis } \\
\text { at } \\
\text { Discharge } \\
\text { If Different } \\
\text { ICD Code } \\
\left(2^{*}\right) \\
\end{array}$ & \\
\hline 1952 & - & - & 8141 & - & - & Fracture of Carpal bones \\
\hline 1953 & - & - & 8540 & - & - & Head injury of other and unspecified nature \\
\hline 1955 & - & - & 8340 & - & - & Dislocation of finger \\
\hline 1956 & - & 21 & 8530 & 3100 & - & Intracranial haemorrhage, borderline intelligence \\
\hline 1957 & - & 20 & 8530 & 9968 & - & $\begin{array}{l}\text { Intracranial haemorrhage injury of other and } \\
\text { unspecified nature }\end{array}$ \\
\hline 1958 & - & 19 & 8141 & - & - & Fracture of carpal bones \\
\hline 1958 & - & 19 & 8520 & - & - & Subarachnoid subdural and extradural haemorrhage \\
\hline 1958 & - & 40 & 2962 & 3007 & - & Depressive, Psychoneurotic disorders \\
\hline 1959 & - & 22 & 8300 & - & - & Dislocation of Jaw \\
\hline 1961 & - & 18 & 8540 & - & - & Head injury of other and unspecified nature \\
\hline 1962 & - & 18 & 376 & 8700 & - & Detachment of retina, open wound of eye and or \\
\hline 1963 & - & 22 & 8120 & - & - & Fracture of humerus \\
\hline 1964 & - & 20 & 8130 & - & - & Fracture of radius and ulna \\
\hline 1964 & - & 23 & 8460 & - & - & Sprains and strains of Sacro-ilias region \\
\hline 1964 & - & 22 & 3899 & - & - & Other deafness \\
\hline 1964 & - & 50 & 8540 & - & - & Head injury of other and unspecified nature \\
\hline 1964 & - & 23 & 8130 & - & - & Fracture of radius and ulna \\
\hline 1968 & 1965 & 23 & 8720 & - & - & Traumatic perforation of ear \\
\hline 1968 & 1967 & 24 & 9500 & - & 9210 & $\begin{array}{l}\text { Injury to optic nerves, contusion of eye and orbit } \\
\text { (sub total blindness) }\end{array}$ \\
\hline 1969 & 1968 & 20 & 8540 & - & 8530 & Intracranial haemorrhage \\
\hline 1970 & 1969 & 25 & 8812 & - & 8819 & Laceration of wrist \\
\hline 1972 & 1972 & 16 & 8360 & - & - & Dislocation of knee \\
\hline 1973 & 1973 & 23 & 8520 & 2250 & - & Subdural haemorrhage, benign neoplasm of brain \\
\hline 1975 & 1973 & 18 & 8519 & - & 8510 & Cerebral laceration and contusion \\
\hline 1976 & 1974 & 20 & 7131 & 9954 & - & Spondylolysis-adhesions and nerve root irritation \\
\hline 1977 & 1976 & 22 & 8529 & 7810 & - & Subdural haemorrhage, disturbance of vision \\
\hline 1978 & 1978 & 17 & 8122 & - & - & Fracture of humerus \\
\hline 1979 & 1979 & 19 & 9580 & 一 & - & Cervical spine injury with nerve root contusion \\
\hline 1980 & 1979 & 21 & 8520 & 3451 & - & Subdural haemorrhage, epilepsy \\
\hline
\end{tabular}


Table IV

Number and Percentage of Cases by Age and Injury Group

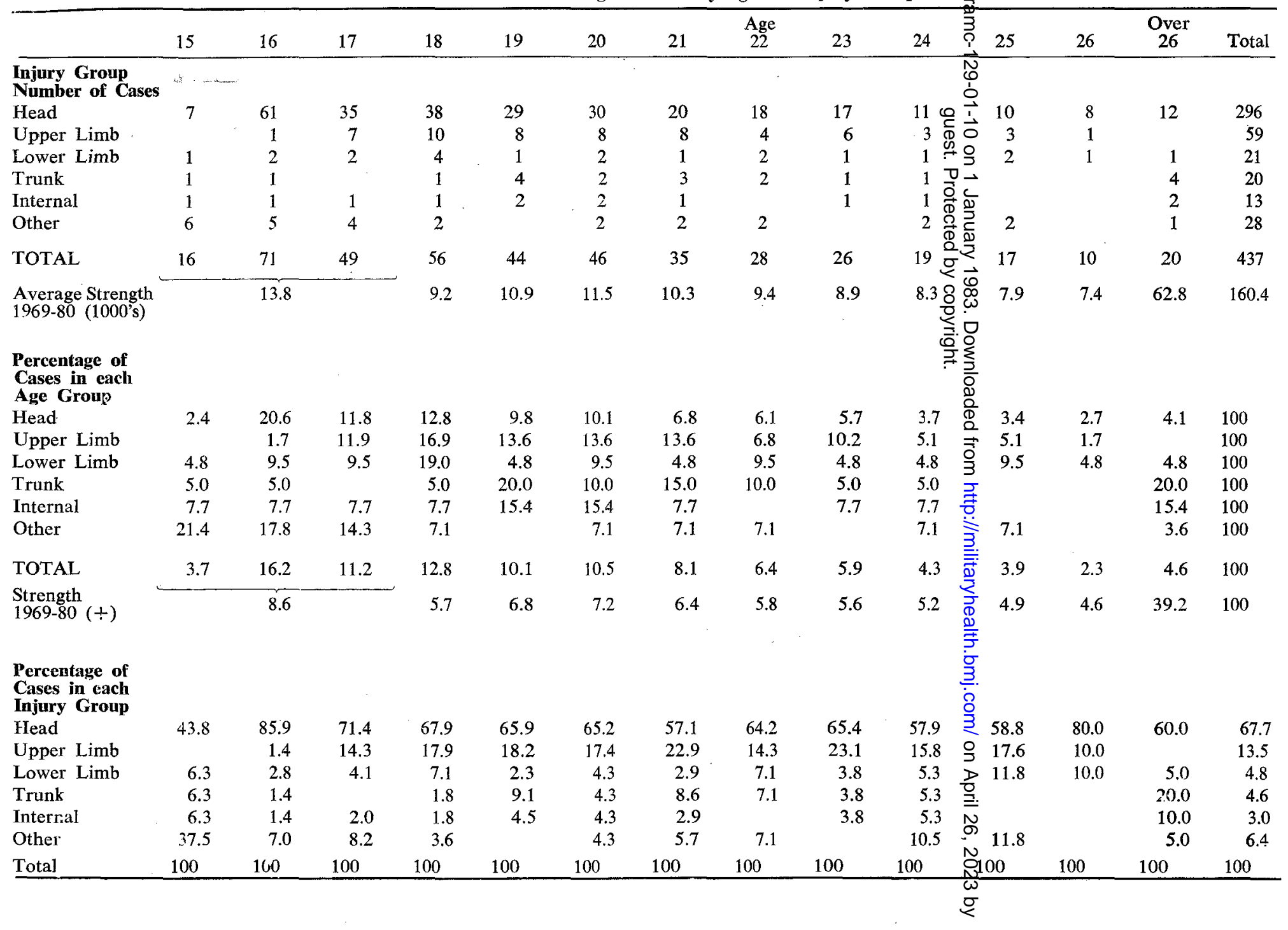


of the long stay cases resulted in medical discharges. $67 \%$ of discharges occurred in a different year from the original injury.

\section{Discussion}

One of the problems with trying to assess how dangerous an activity is lies in estimating the population at risk. Rosenbaum ${ }^{1}$ found that, in 1962, of a random sample of 3185 Army personnel 113 boxed and that they spent on average 4.9 hours a month each boxing (or training).

If the above ratios still hold then throughout the period 1969-1980 there would have been about 5700 boxers in the Army each spending about 59 hours a year boxing. On average there were 35 injuries a year serious enough for admission to hospital and one medical discharge a year so that about one in every 150 boxers is admitted per year or one injury occurs after every 9000 man hours of boxing. These figures are very approximate and the rates are somewhat less than found by Rosenbaum.

With an average length of stay per injury of 10.4 days there will, on average, be one person in hospital at any one time because of a boxing injury.

Without performing a similar study of injuries sustained from other forms of athletic activity (and we are planning to do this) the relative dangers of boxing are impossible to assess. It is interesting to note however that between 1978 and 1980 boxing injuries accounted for $3.6 \%$ of all sports injuries with association football, rugby and skiing accounting for $37.3 \%, 23.8 \%$ and $6.9 \%$ respectively. Rosenbaum found that boxing took $1.6 \%$ of total sports time, football $13.7 \%$, rugby $2.7 \%$ and skiing $2.5 \%$. Thus boxing has a ratio of $2.3: 1$, football $2.7: 1$, rugby $8.8: 1$, and skiing $2.8: 1$, of expected injuries to actual injuries (this ratio is calculated by dividing the number of injuries which would be expected if all sports were equally dangerous into the actual number of injuries). Assuming that individual injuries are equally serious (which is probably not true) then rugby, football and skiing are more dangerous than boxing.

The aim of this paper is not however to compare boxing with other sports but to outline the types of injury received and to highlight the problems arising from them. Head injuries predominated, as would be expected, and concussion was the most common single diagnosis with 115 cases, $39 \%$ of all admissions. Most cases were fairly minor, $57 \%$ of them being of less than 5 days duration, but many in- $\frac{3}{\mathbb{D}}$ juries to the head have secondary and late effects $\propto$ (which we have not been able to quantify) and a? number of the medical discharges did not occuro until well after the original injury.

Table 4 shows the distribution of injuries by $\overrightarrow{\vec{F}}$ injury group amongst the ages 15-26 and over 26:0 The percentages are given in two ways; first as a등 percentage of the injuries within an injury group $\overline{\bar{p}}$ and secondly as a percentage of the total injuries at a given age. Also shown is the distribution of the average strength of the Army from 1969-1980.

It can be seen that while only $8.6 \%$ of the Army $\vec{O}$ strength was less than $18,31.1 \%$ of the injuries occurred to people in that age group. It is not known what proportions of soldiers within each age group participate in boxing therefore it is impos-5 sible to say whether this is significant, however, it? appears that even amongst the younger members $\overrightarrow{0}$ of the Army (up to age 26), who might be expected? to be equally at risk, the injury rate decreases wiohage and thus experience. This is borne out by teo fact that the proportion of injuries which affeeto the head is considerably higher in the younger agegroups than in the older groups. Injuries to thec limbs and trunk appear to increase with age whipes internal injuries remain fairly constant.

Perhaps with so many head injuries occurripg to so many young men some form of head protes $-\infty$ tion should be worn during matches as it is durioget training.

In absolute terms boxing injuries are costing thes Army one medical discharge per year and one perrson in hospital at any one time. In addition there must be many minor injuries which do not result in admission but which may have long term effects $\vec{\rightarrow}$ on the health of the patient. It is not for us to say3 whether this price is too high for the $3.5 \%$ of the Army who participate in the sport.

\section{REFERENCES}

1 Rosenbaum M A. A survey of sport played in the Army. J R Army Med Corps 1967; 113: 65-74.

2 World Health Organization. Manual of the Inter national Statistical Classification of Diseases Injuries and Causes of Death. Geneva 1967; 8 th ed 